\title{
Phytochemical Screening and Antimicrobial Activity of Ethanoic Extract of Passiflora edulis var. flavicarpa Seed on Selected Pathogens
}

\author{
Anulika Mercy Kanu*, Agwu Chukwuemeka Okorie, Chidiebere Uche, Ugochi Nwoke Awa \\ Department of Biology/Microbiology, Abia State Polytechnic, Nigeria
}

Copyright $(2017$ by authors, all rights reserved. Authors agree that this article remains permanently open access under the terms of the Creative Commons Attribution License 4.0 International License

\begin{abstract}
The present situation of drug resistance in the world necessitates the need to intensify researches on the use of alternative strategies for effective control of infections using products obtained from plant extracts. Hence this study was undertaken to evaluate the phytochemical and antimicrobial properties of ethanoic extracts of Passiflora edulis var. flavicarpa seed by testing them against three clinically important pathogens namely: Staphylococcus aureus, Escherichia coli and Candida albicans. Agar diffusion method was used in determining the susceptibility pattern of the different seed extracts concentrations $(25 \%, 50 \%, 75 \%$ and $100 \%)$ on the test organisms (Escherichia coli, Staphylococcus aureus and Candida albicans). The Passiflora edulis var. flavicarpa seed extract was subjected to phytochemical screening for presence of bioactive compounds using standard procedures. From the results, the zone of inhibition of the ethanoic extract at varying concentrations $(100 \%, 75 \%, 50 \%$ and $25 \%$ ) on Staphylococcus aureus ranged from $6 \mathrm{~mm}$ to $18 \mathrm{~mm}$, Escherichia coli $5 \mathrm{~mm}$ to $11 \mathrm{~mm}$ and Candida albicans $5 \mathrm{~mm}$ to $18 \mathrm{~mm}$. The growth of all the organisms was inhibited, through to varying degrees with Staphylococcus aureus and Candida albicans being more susceptible than Escherichia coli. The phytochemical screening revealed the presence of tannins, flavonoids, saponins, alkaloids, steroid, glycosides, saponin glycoside, terpenes and cyanogenic glycosides. The antimicrobial activity of this extract is possibly linked to the presence of flavonoids, alkaloids, steroid, saponins and/or tannins. The result obtained in the study is an indication that passion seed has the potential to be used as a source for new broad spectrum antimicrobials.
\end{abstract}

Keywords Antimicrobial Activity, Passiflora edulis var. flavicarpa, Seed, Extract, Phytochemical Constituents

\section{Introduction}

Infectious disease still remains an important cause of morbidity and mortality in man. In recent years drug resistance in human pathogenic microorganisms has developed and the use of several antibiotics has been ineffective in solving the global problem. Great efforts are being made to reverse this trend and one of them is the widespread screening of medicinal plants from the traditional system of medicine hoping to get some newer, safer and more effective agents that can be used to fight infectious diseases [1].

Plants are known to produce phytochemicals, which are potential sources of anticarcinogenic, anticancer, antimicrobial, and antioxidant activity. The antimicrobial activities of medicinal plants extracts have been linked to the presence of bioactive compounds such as tannins, flavonoids and alkaloids which sometimes serve to protect the plants themselves against bacteria, fungi and viral infections as well as exhibiting their antimicrobial properties on these organisms [2].

The passion fruit tree (Passiflora edulis) belongs to family Passifloraceae [3]. There are two recognized forms of passion fruit: purple ( $P$. edulis Sims) and yellow ( $P$. edulis var. flavicarpa) [4]. The passion flower is a fast growing perennial vine with a thick woody stem. They are mostly vines with some being shrubs and a few species being herbaceous. The species of this genus are distributed in the warm temperate and tropical regions of the world, but they are most rare in Asia, Australia and tropical Africa [5]. The leaves, stems, roots, and fruits of Passiflora species have long been used in folk medicine and are finding an increasingly important place in modern medicine [6].

The $P$. edulis var. flavicarpa fruits are round in shape, with a diameter between 8 and $10 \mathrm{~cm}$ and a green peel at maturity which later turns yellow. The edible part of the passion fruit (40\%) consists of pulp with seeds, and $60 \%$ of the peel consists of mesocarp and epicarp. They contain many seeds (as do the other Passifloraceae species) surrounded by a gelatinous yellow pulp that has an intense aroma and a sweet-acid taste [7]. 
The most economically importance of passion fruit is in the form of concentrated juice [8]; however, for industrialization, passion fruit bark and seeds are usually discarded, and these represent over $60 \%$ of the fruit and are almost always treated as organic waste. An alternative to byproducts from passion fruit industrialization would be its use in production of antimicrobials.

The present situation of drug resistance in the world necessitates the need to intensify researches on the use of alternative strategies for effective control of infection using products obtained from plant extracts. Hence, this study was undertaken to determine the antimicrobial activity of ethanolic extracts of passion seed by testing them against three clinically important pathogens namely; Staphylococcus aureus, Escherichia coli and Candida albicans.

\section{Materials and Methods}

\section{Sample Collection}

The passion fruits were obtained locally from Ofeme in Umuahia North Local Government Area of Abia State in South Eastern Nigeria. The plants were botanically identified in the herbarium section of Department of Biology/Microbiology, Abia State Polytechnic, Aba.
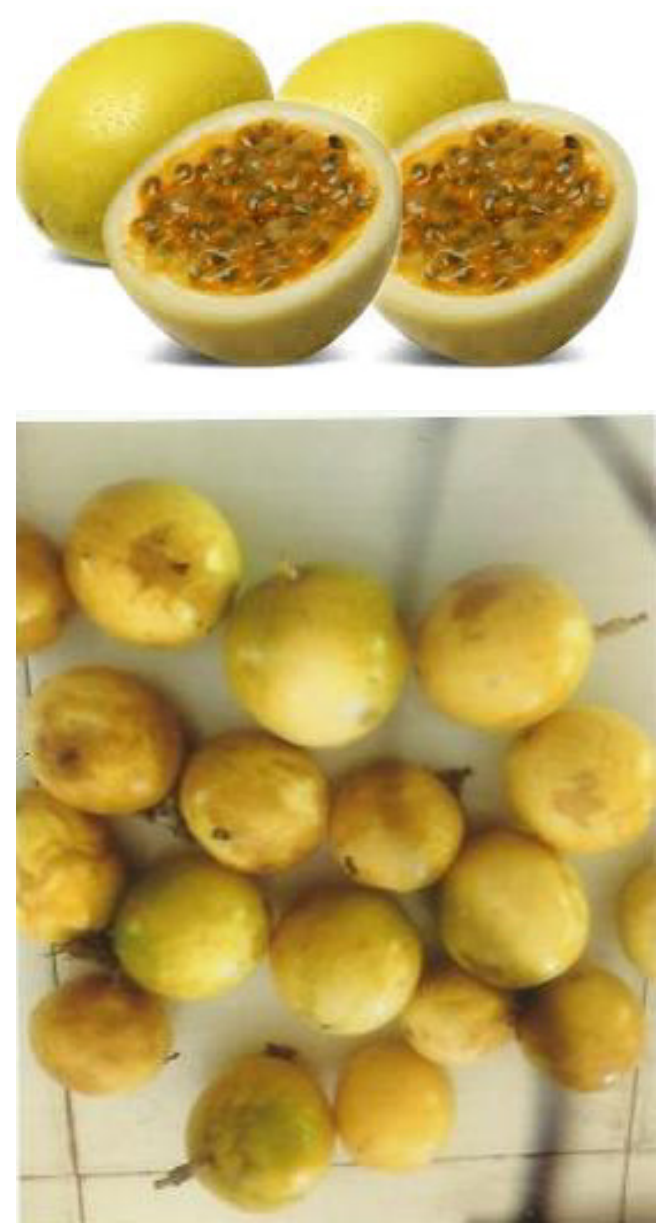

Figure 1. Passiflora edulis var. flavicarpa

\section{Processing of Plant Materials}

The fruits were prepared for use by washing with distilled water, the fruits were cut with a sterile knife and the seeds were obtained. The seeds were dried at room temperature and later dried in an electric oven at $90^{\circ} \mathrm{C}$ for 2 hours after which the seeds were grinded to fine powder using an electric blender.

\section{Preparation of Extracts}

About 25 grams of the powdered seed of passion fruit was extracted with $100 \mathrm{ml}$ of ethanol using soxhlet apparatus for $48 \mathrm{hrs}$. After 48 hours the mixture was filtered into a beaker. The filtrate in the beaker was concentrated to dryness on a water bath at a temperature of $100^{\circ} \mathrm{C}$ (steam temperature). The extract was then stored in a well -sealed dark brown colored glass bottle under refrigerated condition at $4^{\circ} \mathrm{C}$ until use.

\section{Test Organisms}

Escherichia coli, Staphylococcus aureus and Candida albicans were used as the test organisms. The cultures were obtained from a high level private laboratory in Aba, Abia State. The bacteria were subcultured on to Nutrient Agar and Mac Conkey Agar plates while fungi was sub cultured on to Sabouraud dextrose agar and kept at $37^{\circ} \mathrm{C}$ for 24 hours. They were confirmed by Gram staining, Motility, IMViC, Sugar Fermentation (Glucose, Sucrose, Lactose and Maltose), Oxidation-Fermentation, Urease, Nitrate, Mannitol Motility, Triple Sugar Agar, Oxidase, Catalase and Coagulase Tests for both Gram positive and Gram negative bacteria. The cultures from solid media were further inoculated to peptone broth, incubated for 24 hours at $37^{\circ} \mathrm{C}$ and used as the inoculum for the determination of antimicrobial activity.

\section{Antimicrobial Test}

Pure cultures of the 24 hours test organisms were each seeded onto different freshly prepared nutrient agar plates by means of a sterile glass spreader to get uniform distribution of the microorganisms. With the help of a sterile borer, wells of $5 \mathrm{~mm}$ diameter were made in the media at a distance of $1-2 \mathrm{~cm}$ from the periphery of the plates. These plates were labeled and $0.2 \mathrm{ml}$ of each plant extract (at different concentrations of extracts i.e. $100 \%, 75 \%, 50 \%$, and $25 \%$ ) was added aseptically into the well. Then the plates were incubated for 24 hours at $37^{\circ} \mathrm{C}$. The effectiveness of the extract was recorded by measuring the diameter of inhibition zone. The zones of inhibition above $6 \mathrm{~mm}$ diameter of each isolate were used as a measure of susceptibility (positive reading) to the extracts [9].

\section{Phytochemical Screening}

The ethanol extract of Passiflora edulis var. flavicarpa 
seeds were screened for various bioactive compounds including flavonoids, saponins, alkaloids, tannins, steroid, anthraquinones, volatile oil, glycosides, cardiac glycoside, saponin glycoside, balsam, terpenes and cyanogenic glycoside using methods described by Harborne, [10] and Kokate, [11].

\section{Statistical Analysis}

The IBM SPSS version 21 was used for data analysis. Means were compared using one way analysis of variance followed by a post hoc Tukey's test $(p<0.05)$ for mean comparison.

\section{Results}

The result of antibacterial screening of ethanolic extracts of passion seed against test organisms are represented in table 1 . The extract showed variable degrees of antibacterial activity against $S$. aureus, E. coli and Candida albicans. The result indicates that all organisms were found to be more susceptible to higher concentration of the extract. There was no statistical difference between the specified range of concentration of the zones of inhibitions among tested organisms as determined by the one - way Anova, F $(2,9)=$ 2.081, $p=0.180$ ).

A Tukey's post hoc test also revealed that there was no statistical significance between the mean differences at the concentrations of various zones of inhibitions of the tested organisms as that of $S$. aureus $(12.75 \pm 5.12, p=0.172), E$. coli $(5.75 \pm 4.57, p=0.373)$ and $C$. albicans $(10.75 \pm 5.25, p=$ $0.841)$.

Table 1. Antimicrobial activity of ethanolic extracts of passion seed against test organisms.

\begin{tabular}{|c|c|c|c|c|c|}
\hline \multirow{2}{*}{ Organisms } & \multicolumn{4}{|c|}{$\begin{array}{c}\text { Zones of inhibition of various } \\
\text { concentrations }\end{array}$} & mean \pm SD \\
\hline & $100 \%$ & $75 \%$ & $50 \%$ & $25 \%$ & \\
\hline S. aureus & $18 \mathrm{~mm}$ & $15 \mathrm{~mm}$ & $12 \mathrm{~mm}$ & $6 \mathrm{~mm}$ & $12.75 \pm 5.12^{\mathrm{a}}$ \\
\hline E. coli & $11 \mathrm{~mm}$ & $7 \mathrm{~mm}$ & $5 \mathrm{~mm}$ & $\mathrm{Nil}$ & $5.75 \pm 4.57^{\mathrm{a}}$ \\
\hline C. albicans & $18 \mathrm{~mm}$ & $11 \mathrm{~mm}$ & $8 \mathrm{~mm}$ & $6 \mathrm{~mm}$ & $10.75 \pm 5.25^{\mathrm{a}}$ \\
\hline
\end{tabular}

N.B: Values followed by the same super script under the same row are not significantly different

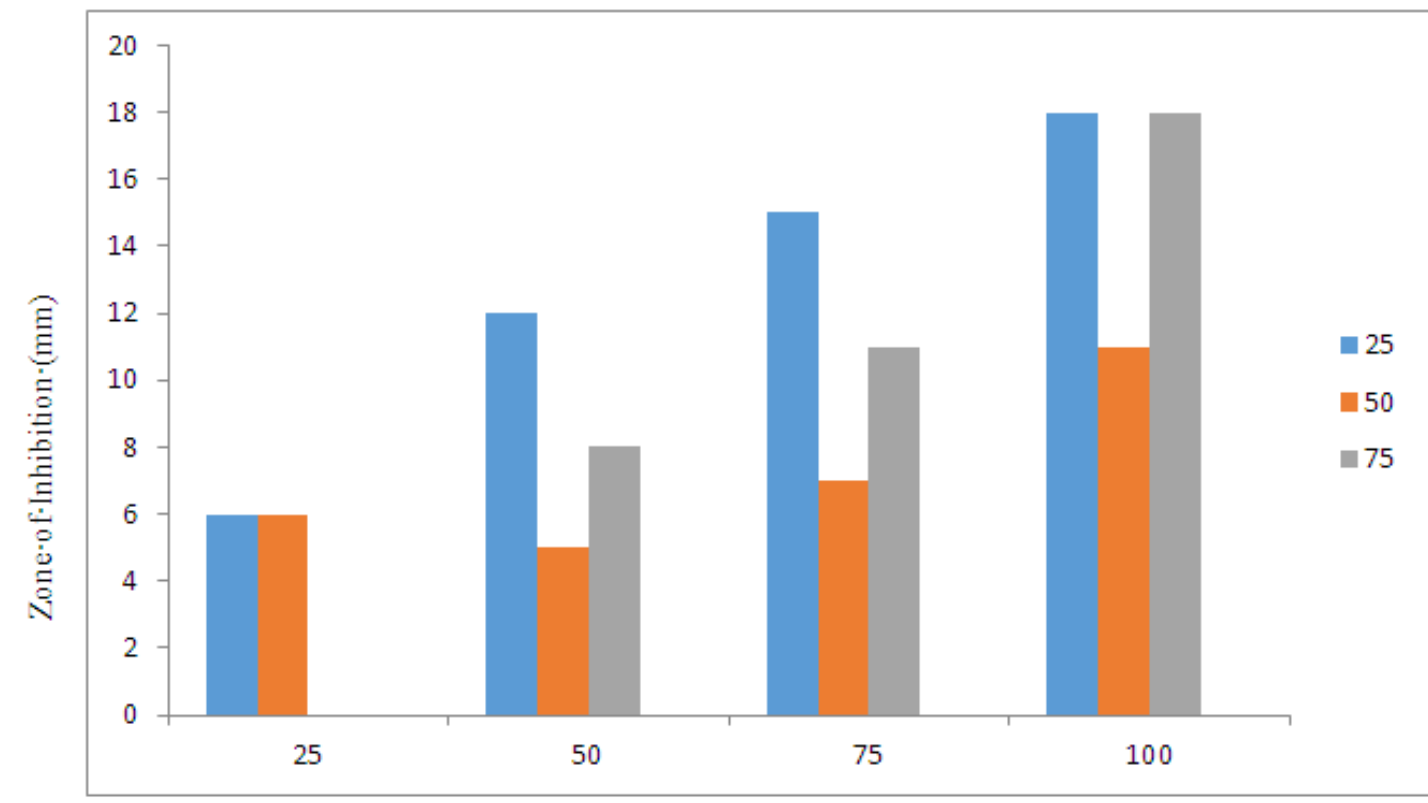

Concentration $\cdot(\%)$

Figure 2. Inhibition Zone of Diameter of Different Concentrations of Ethanoic Extract of Passion Seed 
Table 2. Phytochemical analysis of seed extracts of Passiflora edulis

\begin{tabular}{|c|c|}
\hline Compound groups & Ethanoic extract \\
\hline Flavonoids & + \\
\hline Alkaloids & + \\
\hline Tannins & + \\
\hline Anthraquinones & + \\
\hline Glycosides & + \\
\hline Balsam & + \\
\hline Saponins & + \\
\hline Terpenes & + \\
\hline Steroid & + \\
\hline Volatile oil & + \\
\hline Saponin glycoside & - \\
\hline Cardiac glycoside & + \\
\hline Cyanogenic glycoside & + \\
\hline
\end{tabular}

Key: $+=$ present; $-=$ absent

\section{Discussion}

The antimicrobial activity of ethanoic extract of passion seed was tested on Escherichia coli, Staphylococcus aureus and Candida albicans. The extract showed strong antimicrobial activity against $S$. aureus and C. albicans followed by moderate activity against $E$. coli as shown in the various zones of inhibition observed on agar plates. The result of this study showed that ethanoic extract of passion seed have broad spectrum and magnitude of activity at higher concentration although there was no statistical significance between the mean difference at the concentrations of various zones of inhibition of the tested organisms.

A similar study carried out by Mohanasundari et al. [12] on antibacterial properties of Passiflora foetida found that the ethanolic leaf extract exhibited variable degrees of antibacterial activity against $P$. putida, $V$. cholera and moderate activity was noted in $S$. flexneri and $S$. pyogenes respectively. The result indicated that all the test organisms were found to be more susceptible to higher concentrations of the extract. Also in Mohanasundari et al. [12] work, the ethanolic fruit extract showed moderate activity against the bacterial pathogens namely; $V$. cholera, $P$. putida, $S$. pyogenes and S. flexneri. Wasagu et al. [13] reported the comparative chemical analysis, phytochemical screening and antimicrobial activities of the rinds, seeds and juice of (Passiflora edulis var. flavicarpa) passion fruit on Salmonella typhi, Escherichia coli, Staphylococcus aureus and Aspergillus niger by well-in agar method. The rind and seed showed significant antimicrobial activity against the test organisms. The finding of their study is similar to the present study.

Razia et al. [14] reported that all the extracts of Passiflora edulis showed antimicrobial activity against the pathogenic bacteria tested namely; Escherichia coli, Bacillus subtilis,
Staphylococcus aureus, Pseudomonas aeruginosa, Salmonella typhi, Klebsiella pneumoniae. Similar conclusions were drawn by Aernan et al. [9], who proved that extract of leaf and stem of Passiflora edulis had antibacterial activity against gram negative and gram positive bacteria namely; $S$. aureus, Bacillus spp., Streptococcus spp., Escherichia coli, Salmonella spp. and Shigella spp.

The extract was more active on Gram positive bacteria $(S$. aureus) than Gram -negative bacteria (E. coli) as revealed by zones of inhibition at varying concentrations, although there are some variations. This is agreement with the work of Aernan et al. [9]; Agu et al. [15] and may be attributed to the differences in the cell wall permeability of the two organisms to antimicrobial agents. The cell wall of Gram negative organisms makes them less permeable to antimicrobials as a result of its high lipid content.

Phytochemical analysis is responsible for the identification of components which are responsible for antimicrobial activity of plants. Knowledge of the chemical constituents of plants is desirable because such information will be of value for the synthesis of complex chemical substances. The phytochemical analysis of passion seed extracts revealed the presence of alkaloids, flavonoids, tannins, saponins and several other aromatic compounds. These phytochemical constituents were also reported by Wasagu et al. [13]. The presence of detected phytochemical constituents in seeds of Passiflora edulis var. flavicarpa might be responsible for the observed antimicrobial activity.

This work justifies the therapeutic use of Passiflora in traditional medicine to treat various infectious diseases caused by the microbes. Further research is required to study the active principle, chemical structures and mechanism of action of isolated compounds.

\section{Conclusions}

The findings of the study revealed that the ethanoic extract of passion seed was found to be effective against $S$. aureus, $C$. albicans and E. coli. This suggests that the seed extracts from passion fruit have potentials to serve as a better source of antimicrobial agent.

[1] Natarajan E, Senthilkumar S, Fransis Xavier T and Kalaiselvi V (2003). Antibacterial activities of leaf extracts of Alangium salviifolium. J Trop Med Plants, 4: 9-13.

[2] El-Mahmood AM, Doughari JH and Chanji FJ (2008). Invitro antibacterial activities of crude extracts of Nauclea latifolia and Daniella oliveri. Sci Res Essay, 3: 102-105.

[3] Do Nascimento E, Mulet A, Ascheri J de Carvalhoc and Carcel JA (2016). Effects of high intensity ultrasound on drying kinetics and antioxidant properties of passion fruit peel. $\mathrm{J}$ Food Eng., 170: 108-118.

[4] Hai-xai L, Rong G, Jie Z, Jiao-Jiao Z, Dan-wei Z, Zi-chuan D, 
Tong $\mathrm{Z}$ and Hua-Bin L (2016). Bioactivities of passion fruit. Int J Trad Nat Med, 6(1):26-34.

[5] Ingale AG and Hivrale AU (2010). Pharmaceutical studies of Passiflora spp. and their bioactive compounds. Afri J Plant Sci, 4(10): 417-426.

[6] Shiamala DR, Japar SB and Muta HZ (2014). Assessment of total phenolic, antioxidant, and antibacterial activities of Passiflora species. Sci. World J., 2014: 1-10.

[7] López-Vargas, J. H., Fernández-López, J., Pérez-Álvarez, J. A. and Viuda-Martos, M (2013). Chemical, physico-chemical, technological, antibacterial and antioxidant properties of dietary fiber powder obtained from yellow passion fruit (Passiflora edulis var. flavicarpa) co-products. Food Research Inter, 51(2): 756-763.

[8] Silva RM, Placido GR, Silva MAP, Castro CFS, Lima MS and Caliari M (2015). Chemical characterization of passion fruit (Passiflora edulis f. flavicarpa) seeds. Afr. J Biotechnol, 14(14): 1230-1233.

[9] Aernan PT, Aondofa TJ and Angbian TT (2016). In vitro antibacterial activity of leaf and stem extract of Passiflora edulis (passion fruit) planted in Federal University of Agriculture Markudi, Central Nigeria. IJSR, 5(9): 499-503.
[10] Harborne JB (1998). Phytochemical Methods. Chapman Hall, London. pp 60-66.

[11] Kokate CK (1994). Practical Pharmacognosy. Vallabh Prakashan, New Delhi pp. 107-113.

[12] Mohanasundari C, Natarajan D, Srinivasan K, Umamaheswari, S and Ramachandran A (2007). Antibacterial properties of Passiflora foetida L. - a common exotic medicinal plant. Afri J Biotech., 6(23): 2650-2653.

[13] Wasagu RSU, Lawal M, Amedu AM, Sabir AA, Kabir S, Tukur UG and Zaharadeen A (2016). Comparative Chemical Analysis, Phytochemical screening and antimicrobial activities of the rinds, seeds and juice of (Passiflora edulis var. flavicarpa). J Nat Sci. Research, 6(19):138-143.

[14] Razia M, Beulah and Sivaramakrishnan S (2014). Phytochemical, GC-MS, FT-IR analysis and antibacterial activity of Passiflora edulis of Kodaikanal region of Tamilnadu. World J Pharm Pharmaceutical Sci., 3(9): 435-441.

[15] Agu KC, Igweoha CA and Umeh CN (2013). Antimicrobial activity of the ethanolic and petroleum ether extracts of tangerine seed on selected bacteria. Inter J Agri Biosci., 2 (1): 22-24. 